\title{
Validation and Implementation of Cold Purification Cake Leaching in Ammoniacal Carbonate Solutions at Hindustan Zinc Hydro Refineries
}

\author{
Sundar Saran Sombhatla*, Ashish Kumar, Akhilesh Shukla, Kiran Kumar, Sheeba Mashruwala \\ Central Research \& Development Laboratory, Hindustan Zinc Limited, Udaipur, India \\ Email address: \\ sundar.sombhatla@vedanta.co.in (S. S. Sombhatla), ashish.kumar@vedanta.co.in (A. Kumar), akhilesh.shukla@vedanta.co.in (A. Shukla), \\ kiran.rokkam@vedanta.co.in (K. K. Rokkam), sheeba.mashruwala@vedanta.co.in (S. Mashruwala) \\ ${ }^{*}$ Corresponding author
}

To cite this article:

Sundar Saran Sombhatla, Ashish Kumar, Akhilesh Shukla, Kiran Kumar, Sheeba Mashruwala. Validation and Implementation of Cold Purification Cake Leaching in Ammoniacal Carbonate Solutions at Hindustan Zinc Hydro Refineries. American Journal of Physics and Applications. Vol. 6, No. 2, 2018, pp. 26-34. doi: 10.11648/j.ajpa.20180602.11

Received: December 15, 2017; Accepted: December 27, 2017; Published: January 19, 2018

\begin{abstract}
As a part of regular purification process for zinc leachate, cold purification cake is being generated at Hindustan Zinc refineries. Since the cake is being accumulated as an inventory, a treatment process has been designed to recover the copper in house and utilize it as an activator in zinc flotation circuit. It majorly contains copper (30-40\%) along with zinc (10$20 \%$ ) and cadmium (2\%). With confirmation to the above statement, photomicrographs of purification cake also confirmed the major presence of copper in metallic or oxidized form. In present work ammoniacal carbonate leaching of purification cake followed by solvent extraction using diketone based solvent has been studied under the influence of various parameters viz., temperature, agitation, pulp density, ammonia, $\mathrm{CO}_{2}$ dosages, solvent concentration, and impact of w/s zinc on leaching and solvent extraction. Leaching kinetics determined based on shrinking core model. Chemical reaction at unreacted core was found to be the rate controlling step. The estimated activation energy was found to be $24 \mathrm{KJ} / \mathrm{mol}$. Leached copper has been extracted by solvent extraction with a $\beta$ diketone based solvent and is stripped with sulfuric acid as concentrated copper sulfate solution. The above established R\&D findings are successfully implemented in the Commercial plant with a treatment capacity of two tons of cold purification cake per batch.
\end{abstract}

Keywords: Ammonical Leaching, Kinetics, Solvent Extraction, Activation Energy

\section{Introduction}

Hydrometallurgical processing of zinc concentrates through Roast-Leach-Electrowinning route involves a series of solution purification steps in order to eliminate co-deposition of metals along with zinc in electrowinning step. During this course, cold purification step is performed to eliminate copper from the solution. Cemented copper along with zinc and cadmium is termed as cold purification cake and along with these elements; there are other impurities depending on the type of concentrate that is handled in the refinery. [1] [12].

The purification cake generated at Hydro refineries of Hindustan Zinc through the cold purification route is being sold at under value. As the cake mostly contains copper in metallic/oxidized form, the feasibility of leaching the material within the existing facilities has been studied and validated.

In general oxidative leaching in presence of sulphate medium is opted for oxidized copper ores, copper sulphide concentrates and other copper bearing residues as the leaching will be easier, but during the course of leaching a passive layer of elemental sulfur on copper bearing particles will prevent them from further leaching. Along with the above, unwanted leaching of impurities from the solid phases will be observed and involves further purification treatment of the solution. [2] [3] [13].

Due to their weakly basic and slightly acidic nature, ammonia and ammonium salts can act as a lixiviant for the materials containing gangue minerals. Further, for materials containing copper-iron and iron minerals (chalcopyrite, bornite, pyrite, phyrrhotite) ammonia leaching can be more 
beneficial because of its selectivity. The selectivity means solubilization of desired metals and precipitation of undesirable metals due to their high $\mathrm{pH}$. They can be a good alternative to acidic oxidative solutions, considering the high stability constants of the formed ammonical copper complexes. [4] [5].

The leaching solution is a mixture of ammonium carbonate and ammonium hydroxide and it is preferably carried out in the presence of an oxidizing gas, for example air or oxygen to oxidize cuprous ions into cupric ions. Further, depending on the potential $\mathrm{pH}$ diagram of $\mathrm{Cu}-\mathrm{NH}_{3}-\mathrm{H}_{2} \mathrm{O}$ system, metallic copper can be easily oxidized in an ammonical alkaline solution having $+2 \mathrm{Cu}$ ions. The reaction of the process is as follows. [6] [7]

$$
\begin{gathered}
\mathrm{Cu}^{2+}+2\left(\mathrm{NH}_{3}\right) \rightarrow \mathrm{Cu}\left(\mathrm{NH}_{3}\right)_{2}{ }^{2+} \\
\mathrm{Cu}\left(\mathrm{NH}_{3}\right)_{2}{ }^{2+}+2\left(\mathrm{NH}_{3}\right) \rightarrow \mathrm{Cu}\left(\mathrm{NH}_{3}\right)_{4}{ }^{2+} \\
\mathrm{Cu}+\mathrm{Cu}\left(\mathrm{NH}_{3}\right)_{4}{ }^{2+} \rightarrow \mathrm{Cu}\left(\mathrm{NH}_{3}\right)_{2}{ }^{2+}
\end{gathered}
$$

The overall leaching reaction for metallic copper and oxidized copper in ammonical carbonate solution is given as follows

$$
\begin{aligned}
& 2 \mathrm{Cu}+4 \mathrm{NH}_{4} \mathrm{OH}+2\left(\mathrm{NH}_{4}\right)_{2} \mathrm{CO}_{3}+\mathrm{O}_{2} \rightarrow 2 \mathrm{Cu}\left(\mathrm{NH}_{3}\right)_{4} \mathrm{CO}_{3}+6 \mathrm{H}_{2} \mathrm{O} \\
& 2 \mathrm{CuO}+4 \mathrm{NH}_{4} \mathrm{OH}+2\left(\mathrm{NH}_{4}\right)_{2} \mathrm{CO}_{3} \rightarrow 2 \mathrm{Cu}\left(\mathrm{NH}_{3}\right)_{4} \mathrm{CO}_{3}+6 \mathrm{H}_{2} \mathrm{O}
\end{aligned}
$$

The presence of copper in the form of cupric ammine complex gives the solution a bright blue color. There are also chances for direct reaction between above complex and metallic copper in the purification cake, resulting in the formation of undesired cuprous ion for solvent extraction. If little excess ammonia (more than stoichiometric requirement) maintained in the leachate initially, then it will react with the undesired cuprous ammine ion in the presence of air/oxygen to generate cupric ammine ion favorable for solvent extraction. Due to the above reason it is always advisable that ammonia concentration is maintained in little excess, in order to favor the forward reaction or to enhance cupric amine concentration in leachate.

In the second part of study, extraction of leached copper, attached through coordinating bond with $\mathrm{NH}_{3}$ ligand has been planned through solvent extraction by a diketone based solvent. During extraction ammonia ligands are pushed out and a new chelate complex with diketone based is formed in organic phase. Copper (II) extraction from ammonia solution with diketone extractant is described as below.

$$
\mathrm{Cu}^{2+}(\mathrm{aq})+2 \mathrm{HR}(\mathrm{org}) \leftrightarrow \mathrm{Cu} \mathrm{R}_{2}(\mathrm{org})+2 \mathrm{H}^{+}(\mathrm{aq})
$$

Copper loaded in the solvent will be recovered by stripping the solvent solution with an acidic agent and its reaction is as given below. [8]

$$
\mathrm{R}_{2} \mathrm{Cu} \text { (org) }+2 \mathrm{H}^{+} \text {(aq) } \rightarrow \mathrm{Cu}^{++} \text {(aq) }+2 \mathrm{RH} \text { (org) }
$$

In present paper, to validate the leaching of purification cake via ammonical leaching, effect of temperature, agitation speed, particle size, pulp density, leaching kinetics, activation energy, effect of water soluble zinc on leaching and solvent extraction trials were studied. The copper sulphate thus produced after stripping the loaded organic will be used as an activator in froth flotation for sphalerite concentrates as this forms a passive coating on Zinc Sulphide particle and actively responds to the collector.

\section{Materials and Methods}

\subsection{Material}

Cold purification cake sample used in these studies has been received from Hydro refineries of Hindustan Zinc Limited. Received solid samples were with moisture content, so initially they were washed, dried, ground and sieved with standard ASTM test sieves, and individual copper content has been estimated. Maximum amount of fraction has been retained in between $50-75 \mu \mathrm{m}$. Sieve fractions mentioned in Table 1. Leaching trials with or without initial sample grinding hasn't shown any impact on $\mathrm{Cu}$ leaching recoveries, so received sample has been used as such in all experimental trials unless until stated.

Table 1. Sieve fractions and copper assay distribution.

\begin{tabular}{llll}
\hline \multicolumn{2}{l}{ Sieve characteristics } & Input $-\mathbf{1 0 0}$ gms & \\
\hline Mesh \# No. & Particle size $\boldsymbol{\mu m}$ & Weight retained (gms) & $\mathbf{\% ~ C u}$ \\
\hline+50 & 300 & 0 & - \\
+70 & 212 & 0.5 & - \\
+100 & 147 & 1 & - \\
+200 & 74 & 5 & $25 \%$ \\
+300 & 53 & 9.5 & $27 \%$ \\
-300 & -53 & 83.5 & $31 \%$ \\
\hline
\end{tabular}

Ammonia $25 \%$ solution and ammonium carbonate Merck make GR grade, Triple distilled water from Infusil make apparatus; carbon dioxide $100 \%$ pure and compressed air were used in the preparation of leaching media. The optical microscopy of polished sample was done with Leitz Wetzlar Ortholux II pol-BK universal optical microscope. $\mathrm{pH}$ values were monitored with Eutech $\mathrm{pH} 700$ using a refillable glass double junction electrode. Solvent extraction experiments were carried out with the help of a $250 \mathrm{ml}$ separating funnel. Hydrocarbon based Arol light has been used as a diluent.

Table 2. Chemical assay of the received purification cake samples.

\begin{tabular}{ll}
\hline Copper Cement & \\
\hline Element & \% Composition \\
\hline Copper $\mathrm{Cu}$ & $30-35$ \\
$\mathrm{Zinc} \mathrm{Zn}$ & $16-18$ \\
$\mathrm{Cadmium} \mathrm{Cd}$ & $1.5-2$ \\
$\mathrm{~W} / \mathrm{s} \mathrm{Zinc}$ & $6-7$ \\
$\mathrm{SO}_{4}{ }^{2-} / \mathrm{s}$ Sulphates & $15-16$ \\
$\mathrm{Manganese} \mathrm{Mn}_{\text {Antimony Sb }}$ & $0.3-0.4$ \\
Loss on Ignition & $1.5-2.5$ \\
\hline
\end{tabular}




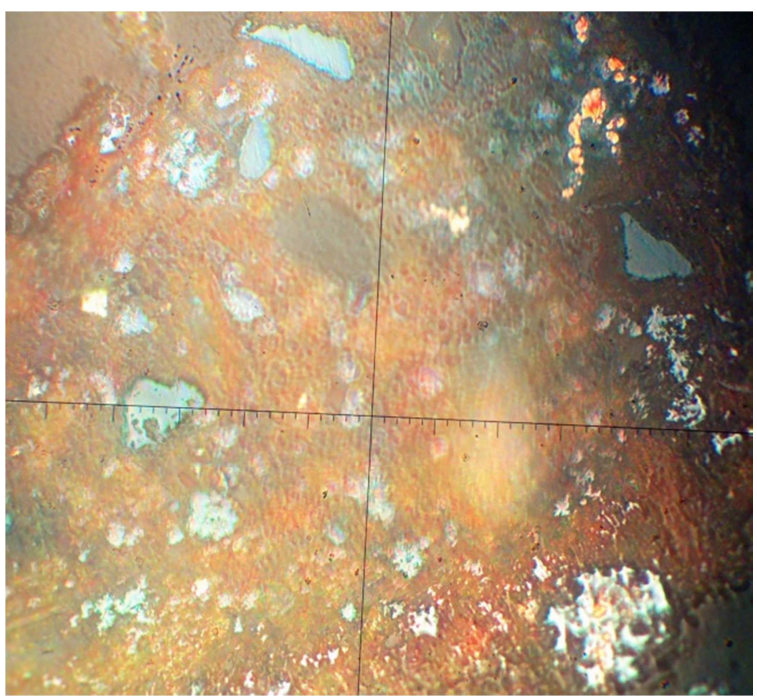

Figure 1. Photomicrograph of polished cake sample.

The optical microscopy image of the polished bulk sample in Figure 1 was recorded using a Leitz Wetzlar Ortholux II pol-BK universal optical microscope under plain polarized refractive light. Native $\mathrm{Cu} 5-20 \mu$ in size is visible in the micrograph and oxidation of native copper is predominantly observed on the peripheral boundaries. A brownish red tint for native $\mathrm{Cu}$ and a sort of bluish grey tint for copper in oxidized form were observed.

\subsection{Method}

All leaching experiments were carried in a specially designed compact 2 liter glass reactor with a top driven agitator and a lid to control evaporation losses in temperature based trials. After maintaining of total volume around 1 liter with distilled water, ammonia \& $\mathrm{CO}_{2}$ reagents were added. $\mathrm{pH}$ was maintained in between 9-9.5, and if the range exceeds, it was controlled by $\mathrm{CO}_{2}$ addition. Once the platform was set for reaction, calculated quantity of solid sample was added to the solution. Excess air purging was avoided during the course of reaction, in order to prevent ammonia losses through vaporization. Aliquots of $5 \mathrm{ml}$ samples of solution were collected periodically, filtered and analyzed to know the copper leaching trend. Final leaching recovery has been calculated based upon the remaining copper content in leached residue on dry weight basis. Recovery calculation is as follows.

$$
\% \mathrm{Cu} \text { recovery }=(\text { copper present in leached and dried cake }) \times 100 /(\text { copper in input cake })
$$

\section{Results \& Discussion}

In leaching studies of a solid particle, kinetic studies plays a predominant role, as it finalizes the type of reactor, volume, mode of flow etc. for a reaction to proceed. Variables such as temperature, agitation speed, and particle size, solid to liquid ratio (pulp density), retention time, and pressure are the key parameters to be monitored for performing kinetic studies. Leaching kinetics were determined with plots between conversion fractions versus reaction time. Across varied parameters, kinetic analysis is performed using liquid solid heterogeneous models. It is clearly evident that conversion rate increases with an increase in temperature (Arrhenius equation), along with reactant concentration and a decline in solid to liquid ratio.

\subsection{Washing of Cu Cement}

The purification cake received was generated through the cold purification process and hence it consists of appreciable amount of water soluble zinc and free acid. The w/s zinc present in cement might affect the leaching process by getting dissolved in to the leachate and hindering the process of $\mathrm{Cu}$ solvent extraction. In order to mitigate the above problem initial water wash has been proposed at ambient conditions.

Table 3. Washing of Purification cake.

\begin{tabular}{lllllll}
\hline \multirow{2}{*}{ Cu Cement I/P gms } & \multirow{2}{*}{ Pulp Density g/l } & \multirow{2}{*}{ Retention time Hrs. } & \multicolumn{3}{c}{ Filtrate } & \multicolumn{2}{c}{ Residue } \\
\cline { 3 - 6 } & & & Zn g/l & pH & Cu\% & Zn\% \\
\hline 1000 & 300 & 0.5 & $11-13$ & 3.6 & $12-13$ \\
300 & 300 & 01 & $13-15$ & 3.7 & $32-35$ \\
300 & 300 & 01 (in presence of caustic) & 1 & $4-4.5$ & 28 & $12-13$ \\
\hline
\end{tabular}

The results in table 3 depict a reduction in w/s zinc from 6$7 \%$ initially to $0.5-0.75 \%$ finally. The washed residue with depleted w/s zinc and enriched copper content was processed for ammoniacal carbonate leaching. Washing in presence of caustic was attempted but at that $\mathrm{pH}$, no impact on $\mathrm{w} / \mathrm{s}$ zinc recovery was observed.

\subsection{Effect of Ammonia and Carbon Dioxide Dosages}

Keeping the temperature constant at $338.15 \mathrm{~K}\left(65^{\circ} \mathrm{C}\right)$, concentration of ammonia and carbon dioxide kept fixed for each trial and their effect on $\mathrm{Cu}$ recoveries has been investigated at different time intervals. The behavior of their dosages can be better understood through the below given plot in figure 2. During the trials, $\mathrm{NH}_{3}$ concentration has been varied from $(0.8 \mathrm{~mol} / \mathrm{l}-3 \mathrm{~mol} / \mathrm{l})$ and $\mathrm{CO}_{2}$ dosages varied from $(2 \mathrm{gm} / 1-10 \mathrm{gm} / \mathrm{l})$.

From the plot, it is evident that $\mathrm{Cu}$ recovery pattern is very substandard at lower $\mathrm{NH}_{3}$ and $\mathrm{CO}_{2}$ concentrations (0.8-1.35 $\mathrm{mol} / 1,2-4 \mathrm{gm} / \mathrm{l})$. With an increase in $\mathrm{NH}_{3}$ and $\mathrm{CO}_{2}$ concentrations, $\mathrm{Cu}$ recovery has been improved and reached its maximum along with retention time. No impact on recoveries has been observed as reagent dosages increased $\left(\mathrm{NH}_{3}>2 \mathrm{~mol} / \mathrm{l}, \mathrm{CO}_{2}>6 \mathrm{gm} / \mathrm{l}\right)$ no impact on recoveries has been observed. Hence, they were selected as the optimal dosages for further trials. 

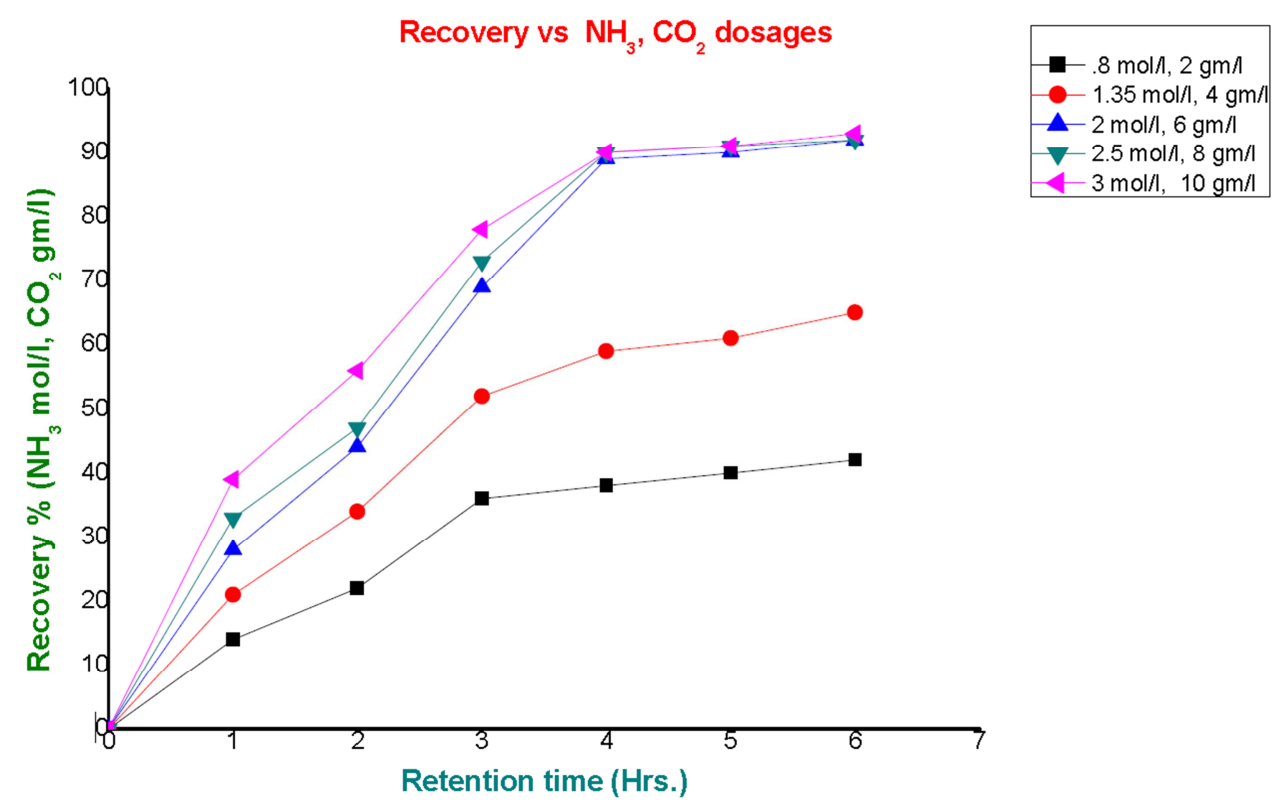

Figure 2. Effect of Reagent concentration on\% Recovery.

\subsection{Effect of Temperature}

Due to the exponential relation of temperature with rate constant in Arrhenius equation, determining optimal temperature for leaching phenomena is a predominant step and the activation energy calculated depending on the optimal temperature may even decide the rate controlling step for leaching kinetics. Keeping the $\mathrm{NH}_{3}$ and $\mathrm{CO}_{2}$ dosages, RPM, pulp density fixed at $2 \mathrm{~mol} / \mathrm{l}, 6 \mathrm{gm} / \mathrm{l}, 70$ and
$50 \mathrm{~g} / \mathrm{l}$ for all trials, temperature was varied from $293.15 \mathrm{~K}$ $\left(20^{\circ} \mathrm{C}\right)$ to $363.15 \mathrm{~K}\left(90^{\circ} \mathrm{C}\right)$. Recoveries of $\mathrm{Cu}$ in to the solution have shown similar behavior for all temperatures from and above $313.15 \mathrm{~K}\left(40^{\circ} \mathrm{C}\right)$. A slender increment in temperature of $2-3^{\circ} \mathrm{C}$ has been observed during the entire course of reaction. From figure 3, temperature of $313.15 \mathrm{~K}$ $\left(40^{\circ} \mathrm{C}\right)$ is optimized, as no further significant increment has been observed beyond this value.

\section{Temperature vs Recovery}

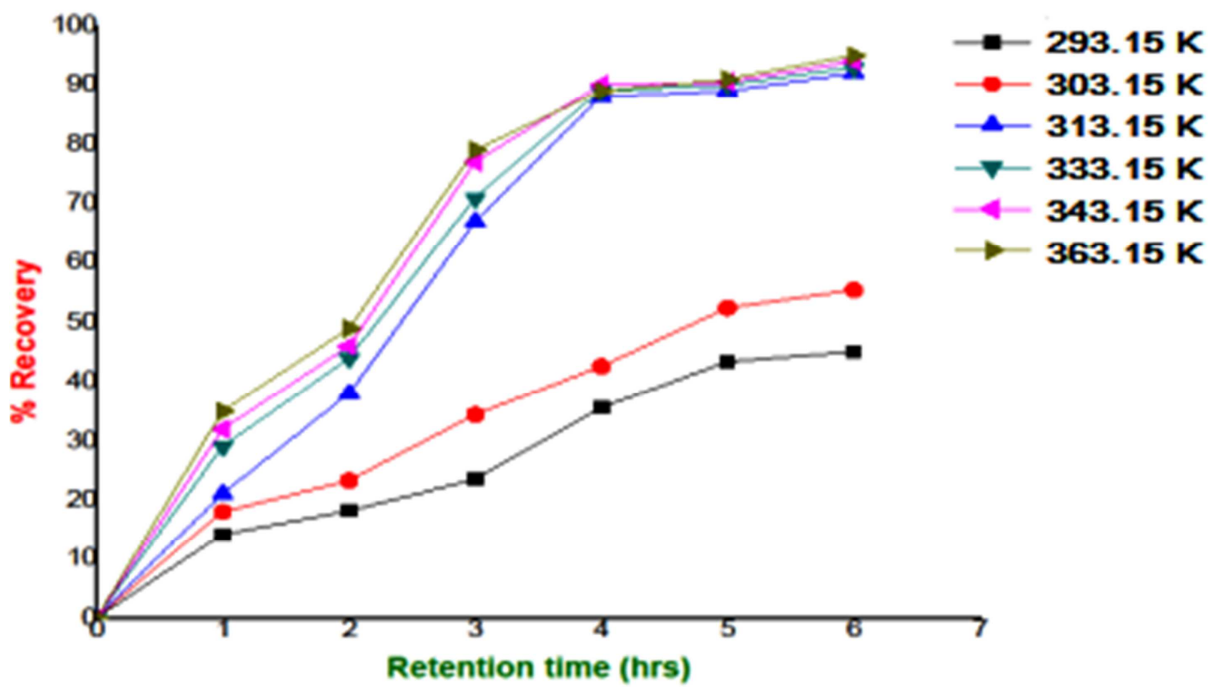

Figure 3. Effect of Temperature on\% Recovery.

\subsection{Effect of Agitation}

Direct impact on $\mathrm{Cu}$ recoveries with increment in agitation RPM from 20-100 has been observed keeping $\mathrm{NH}_{3}$ and $\mathrm{CO}_{2}$ dosages, pulp density and temperature fixed at $2 \mathrm{~mol} / \mathrm{l}, 6$ $\mathrm{gm} / \mathrm{l}, 50 \mathrm{~g} / \mathrm{l}$ and $40^{\circ} \mathrm{C}$. From the figure 4 , a significant rise in dissolution rate observed when RPM varied from 20-80 and it did not change much after 80 RPM. Hence for further trials agitation power of 80 RPM has been maintained. 


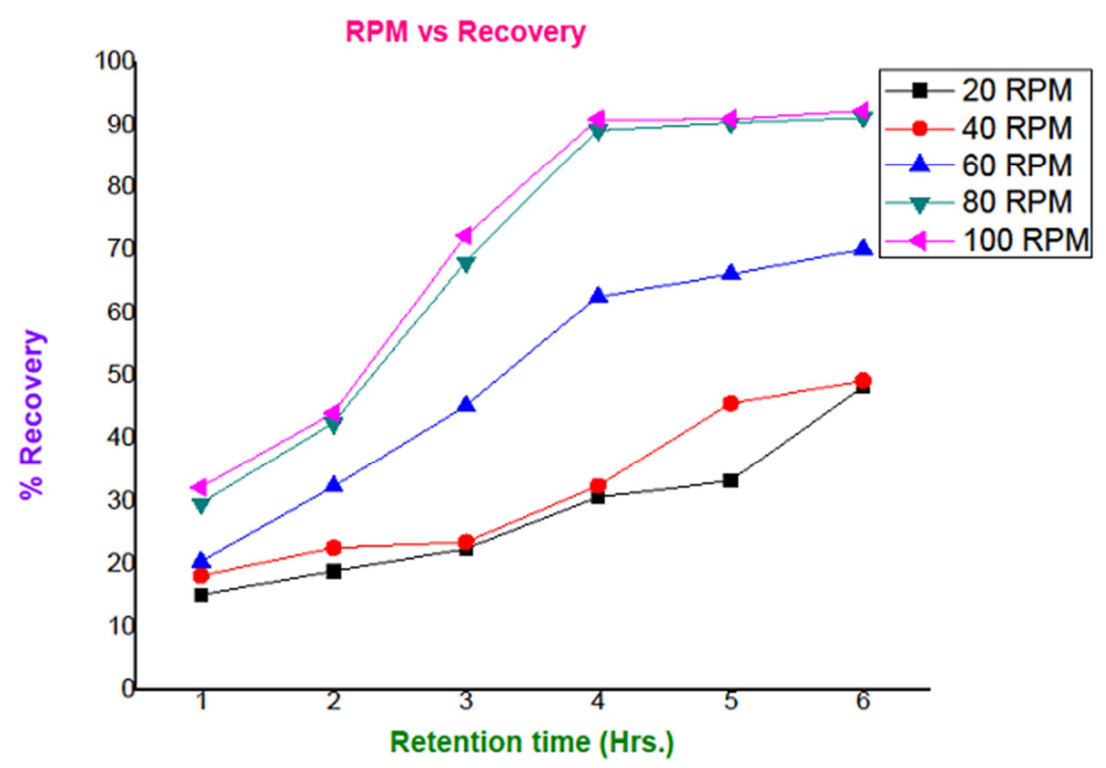

Figure 4. Effect of Agitation RPM on \% Recovery.

With increase in agitation, the thickness of boundary layer decreases creating a turbulent zone so that the dissolution of the solid particle in to the leachate eases. From the above plot it can be stated that reaction might be film diffusion controlled or else product layer diffusion controlled. But a final conclusion can only be drawn once the kinetic characterization has been done though shrinking core model.

From all above plots, it is clearly evident that upon varying various parameters, no appreciable increase in $\mathrm{Cu}$ recoveries were found after $4 \mathrm{hrs}$. of retention time and they almost remained unchanged. Hence retention time of 4 hrs. has been chosen for commencing trials.

\subsection{Effect of Pulp Density}

Pulp Density (Solid to liquid ratio) has clearly shown the impact on leaching of copper in to ammonical solution. In general recoveries of a particular solid in to a leachate shall enhance when the solid to liquid ratios is maintained on a lower side. Leaching trials have been carried with varied pulp densities keeping temperature, agitation RPM, retention time, $\mathrm{NH}_{3}, \mathrm{CO}_{2}$ dosages and air flow rate fixed at $313.15 \mathrm{~K}\left(40^{\circ} \mathrm{C}\right)$, $80,4 \mathrm{hrs}$., $2 \mathrm{~mol} / \mathrm{l}, 6 \mathrm{gm} / 1$ and 0.25 to $1.0 \mathrm{LPM}$. The results are mentioned in the below figure 5 .

A negative impact on $\mathrm{Cu}$ recoveries has been observed with increase in pulp densities. Maximum recovery of $91 \%$ observed at a pulp density of $60 \mathrm{~g} / \mathrm{l}$ at $4 \mathrm{hrs}$. of retention time and a minimum of $59 \%$ was observed at a pulp density of $100 \mathrm{~g} / \mathrm{l}$ at the same retention time. However recoveries can be enhanced to a higher extent for higher pulp densities with an appreciable increment in reagent dosages, agitation speed but they incurs an additional expenditure and an unsafe atmosphere to handle the process due to pungent order of ammonia.

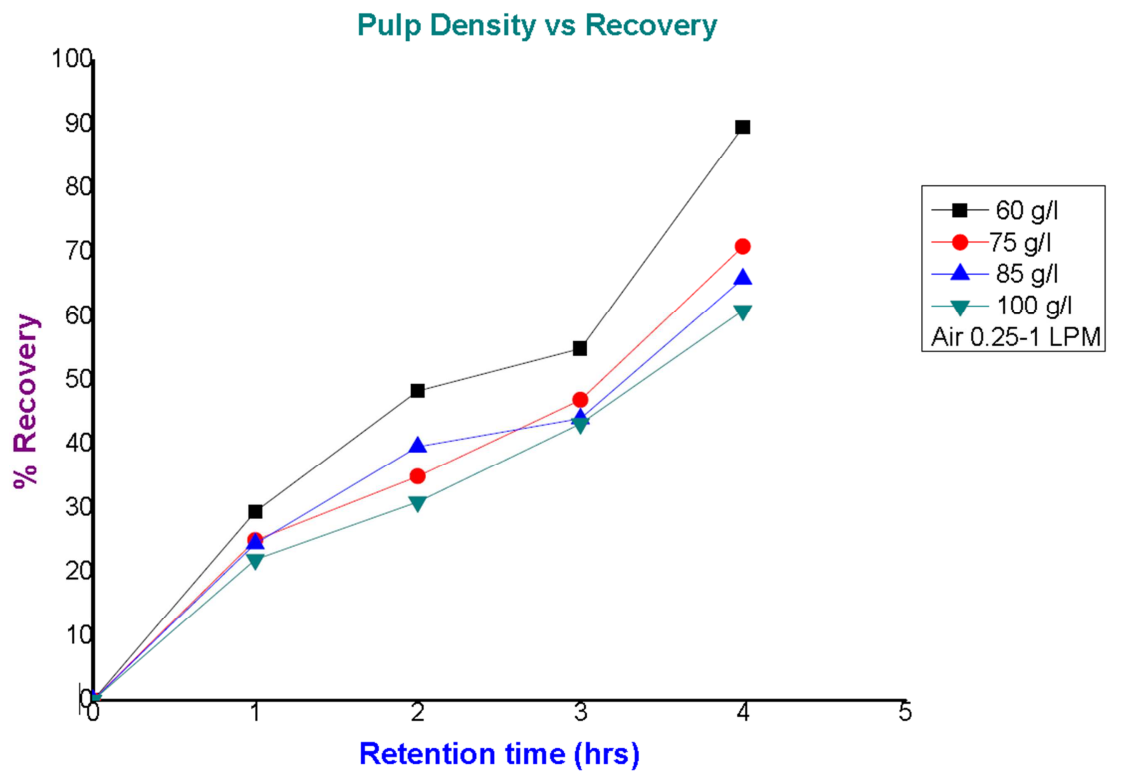

Figure 5. Effect of Pulp Density on \% Recovery. 


\subsection{Reaction Kinetics}

For any heterogeneous kind of reaction (solid-liquid) the overall rate is controlled or guided by the mass transfer rate of reactants and products between bulk fluid and the solid surface. Considering the above experimentation as a heterogeneous solid liquid phase interaction, shrinking core model have been validated to the generated data for determining the rate control step. This model assumes that the reaction between the solid and liquid reactants occurs on the outer surface of the solid particle. It is considered that the reacting particles are spherical and their size does not change during the reaction. As the reaction proceeds, the unreacted core of solid particles shrinks toward the center of the solid and a porous ash layer may be formed around the unreacted core. [9]

$$
\mathrm{A}_{\text {fluid }}+\mathrm{bB}_{\text {solid }} \rightarrow \text { Products. }
$$

Limitations for shrinking core model were given below.

a) Diffusion of fluid reactants from bulk fluid to particle surface via fluid film.

b) Diffusion of reactants across the product layer to the unreacted core.

c) Surface reaction between fluid reactant and solid particle on the unreacted core.

In general, if the rate is controlled by diffusion then the extraction of metal in to leachate can be increased by mixing with increase in speed of agitator. But it cannot be so and even surface reaction at the unreacted core can also be a rate controlling step. For a particle reacting under shrinking core mode, the integrated rate equations for three different rate controlling mechanisms can be written as follows.

a) For film diffusion controlled

$$
\begin{gathered}
\mathrm{X}=\mathrm{K}_{\mathrm{f}} \mathrm{t} \\
\mathrm{K}_{\mathrm{f}}=3 \mathrm{bK}_{\mathrm{c}} \mathrm{C}_{\mathrm{A}} /\left(\rho_{\mathrm{s}} \mathrm{r}_{\mathrm{o}}\right)
\end{gathered}
$$

b) Product layer diffusion controlled

$$
\begin{gathered}
(1-\mathrm{x})-(1-\mathrm{x})^{\wedge}(2 / 3)=\mathrm{K}_{\mathrm{d}} \mathrm{t} \\
\mathrm{K}_{\mathrm{d}}=2 \mathrm{~b} D_{e} \mathrm{C}_{\mathrm{A}} /\left(\rho_{\mathrm{s}} \mathrm{r}_{\mathrm{o}}{ }^{2}\right)
\end{gathered}
$$

c) Surface reaction controlled

$$
\begin{gathered}
1-(1-\mathrm{x})^{\wedge}(1 / 3)=\mathrm{K}_{\mathrm{r}} \mathrm{t} \\
\mathrm{K}_{\mathrm{r}}=\mathrm{bK}_{\mathrm{s}} \mathrm{C}_{\mathrm{A}} /\left(\rho_{\mathrm{s}} \mathrm{r}_{\mathrm{o}}\right)
\end{gathered}
$$

To determine the rate controlling mechanism and kinetic parameters, the experimental conversion data was analyzed on the basis of shrinking core model. At first, conversion vs time data has been plotted against film diffusion control but the model did not fit well. Further the conversion vs time data against various temperatures has been plotted against product layer diffusion and surface reaction control. The data comprehensively fitted at best for surface reaction control with $\mathrm{R}^{2}=0.92$. From the figure 6 , a linear relationship has been yielded for the experimental data proving that above investigation obeys surface reaction control mechanism for shrinking core model.

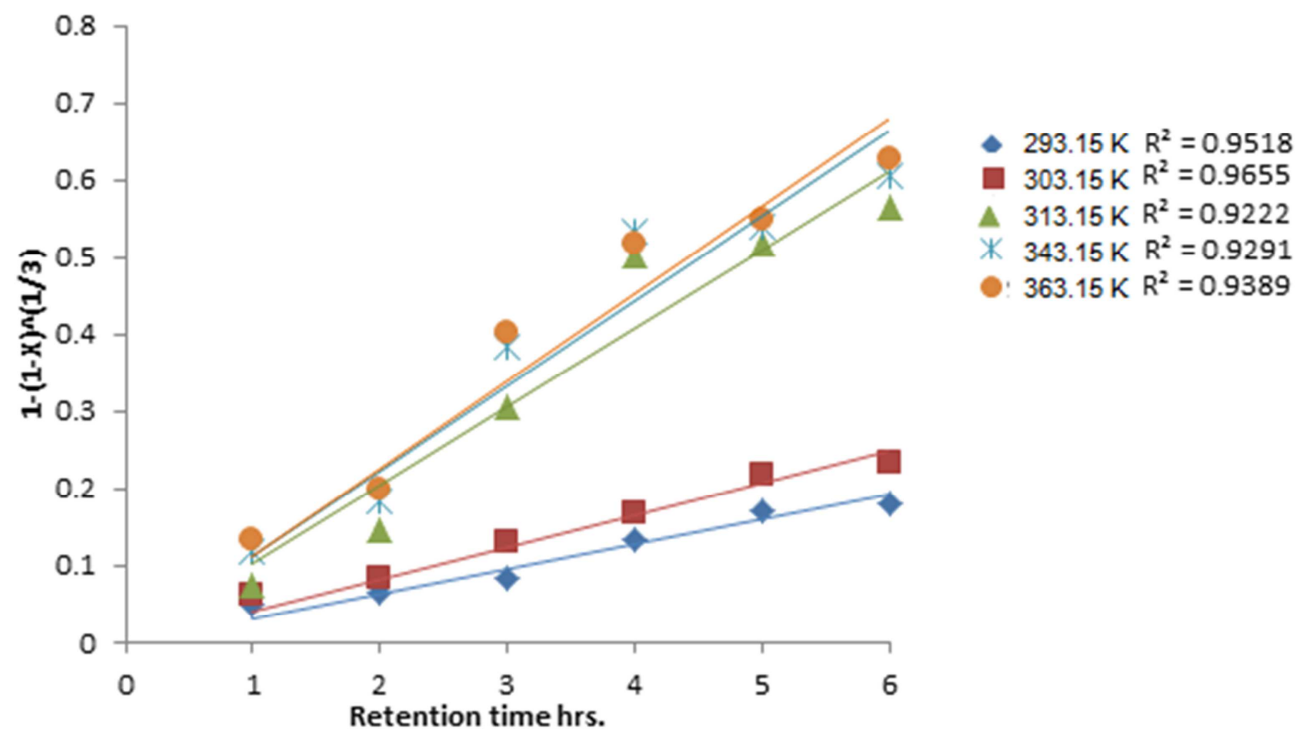

Figure 6. Plot of $1-(1-X)^{\wedge}(1 / 3)$ vs retention time at different temperatures.

The minimum energy required by the potential reactants to participate in a chemical reaction is termed as Activation energy and it is given by the Arrhenius equation $\mathrm{K}_{\mathrm{r}}=\mathrm{A} \exp$ [$\left.\mathrm{E}_{\mathrm{a}} / \mathrm{RT}\right]$. Apart from empirical formula, activation energy can also be determined by a plot between logarithmic function of rate constants and the inverse function of temperature denoted in kelvin. From the figure 7, plotted below calculated activation energy is $23 \mathrm{KJ} / \mathrm{mol}$. Which further confirm that the kinetics are chemical reaction controlled, as same has been predicted in other publications [10]. 


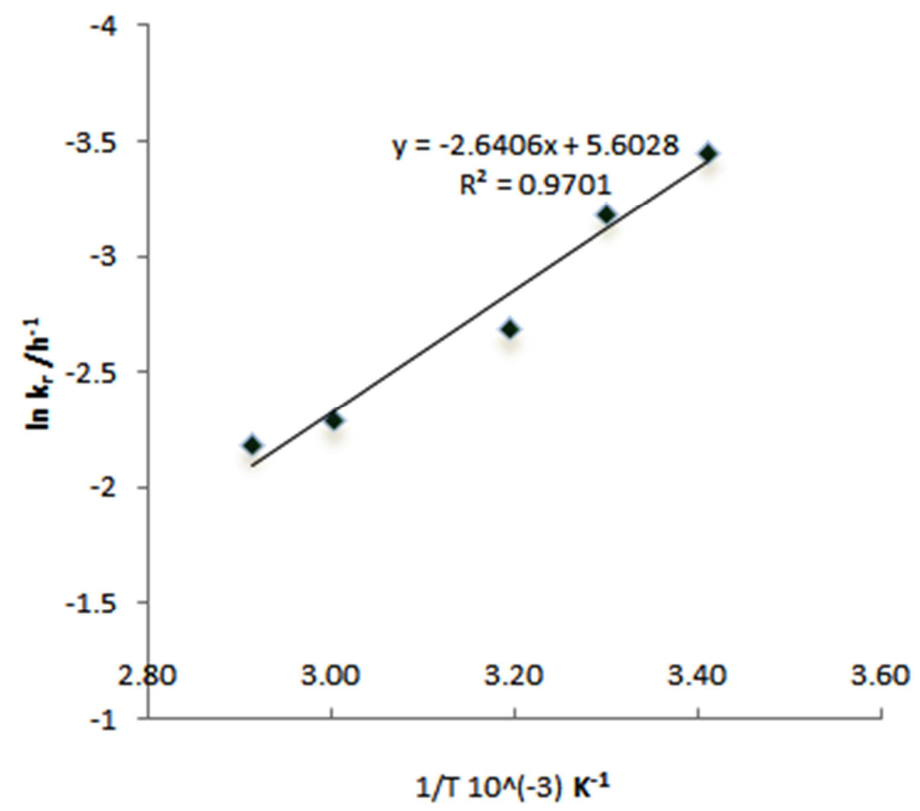

Figure 7. Arrhenius Plot for Reaction kinetics.

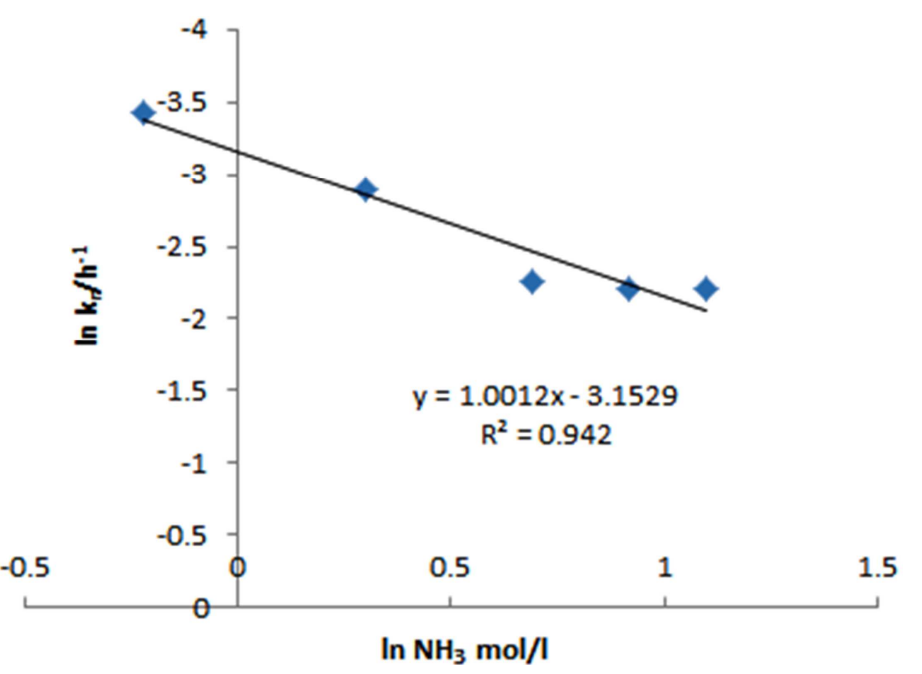

Figure 8. Plot for reaction order vs. $\mathrm{NH}_{3}$ concentration.

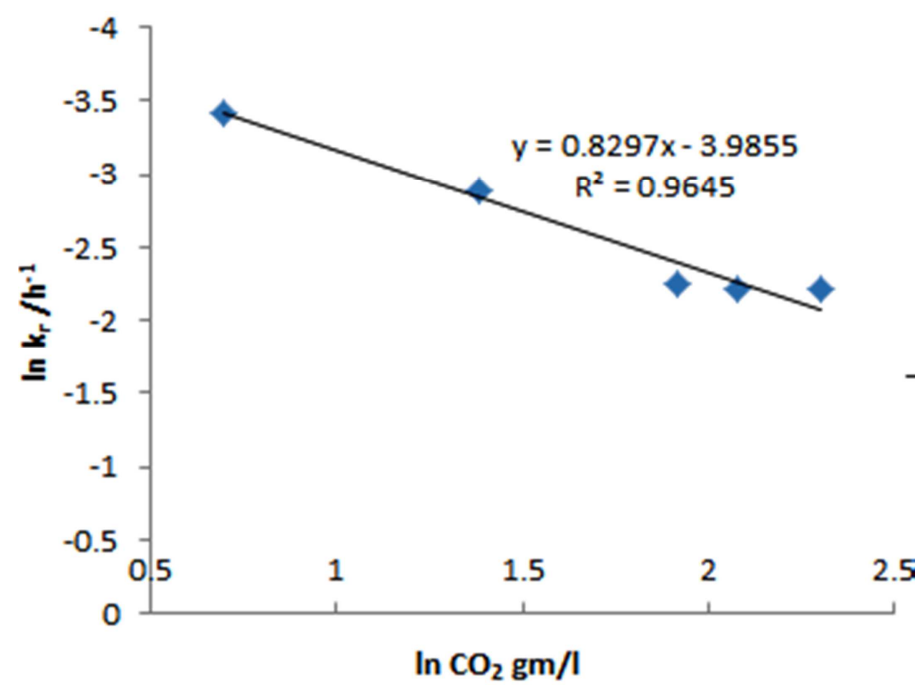

Figure 9. Plot for reaction order vs. $\mathrm{CO}_{2}$ concentration. 
To predict the order of the overall reaction, rate equation controlled by chemical reaction has been applied to the conversion data for various ammonia and $\mathrm{CO}_{2}$ concentrations at different time intervals. The rate constants derived from the slopes were plotted as a logarithmic function against the logarithmic function of ammonia and carbon dioxide concentrations. From figure 8, the kinetics data for chemical reaction control has been fitted well for ammonia concentrations and the order has been determined as 1.0 with a correlation coefficient as 0.94 . From figure 9 the predicted reaction order (slope of the plot) with respect to $\mathrm{CO}_{2}$ is found to be 0.836 with a correlation coefficient of 0.96 . However at higher concentrations the rate is independent as there is no increase in $\mathrm{Cu}$ recoveries.

\subsection{Leaching Followed by Solvent Extraction}

With adhering to optimized parameters finalized in above sections, continuous trials have been performed, which involves leaching followed by solvent extraction. The results have been tabulated in table 4 below. During all the trials, washed and same amount of cold purification cake has been used.

From table 4, mentioned below it is evident that leaching recoveries are quite good with $\mathrm{Cu}$ perspective. W/s zinc getting leached in to the filtrate is in minute quantities as the input cake got washed before leaching. However, Zinc leaching is getting mitigated by precipitation in the form of zinc hydroxide/zinc carbonate once the $\mathrm{CO}_{2}$ is purged into Ammonia lixiviant. [11]

Table 4. Cyclic leaching trials for CP cake.

\begin{tabular}{|c|c|c|c|c|c|c|c|c|c|}
\hline \multicolumn{2}{|c|}{ Raffinate } & \multirow{2}{*}{ Initial pH } & \multicolumn{3}{|c|}{ Filtrate g/l } & \multicolumn{4}{|c|}{ Residue\% } \\
\hline $\mathrm{Cu} \mathrm{g/l}$ & Zn g/l & & $\mathbf{C u}$ & $\mathrm{Zn}$ & Cd & $\mathbf{C u}$ & Zn & Cd & $\operatorname{Rec} \%$ \\
\hline 3.5 & 1.14 & 9.6 & 23.3 & 1.23 & 0.073 & 2.88 & 21.16 & 0.42 & 90.12 \\
\hline 2.78 & 1.21 & 9.5 & 30.2 & 1.41 & 0.07 & 4.35 & 20.42 & 2.24 & 89.81 \\
\hline 1.2 & 1.16 & 9.6 & 29.9 & 1.39 & 0.04 & 3.78 & 21.08 & 1.01 & 91 \\
\hline 1.09 & 1.2 & 9.7 & 25.7 & 1.51 & 0.09 & 2.83 & 21.12 & 0.45 & 88.83 \\
\hline 2.47 & 1.43 & 9.5 & 27.2 & 1.61 & 0.02 & 3.7 & 17.46 & 0.48 & 91.2 \\
\hline
\end{tabular}

I Cu- 30-35\%, Air 0.25 LPM, RT- 4 hrs. PD - 60 g/l, NH $\mathrm{NH}_{3}-2$ mol/1, $\mathrm{CO}_{2}-6$ gm/l.

$$
2\left[\mathrm{Zn}\left(\mathrm{NH}_{3}\right)_{4}\right]^{2+}+4 \mathrm{H}_{2} \mathrm{O}+\mathrm{CO}_{3}{ }^{2-} \leftrightarrow \mathrm{Zn}(\mathrm{OH})_{2} \cdot \mathrm{ZnCO}_{3}+4 \mathrm{NH}^{4+}+2 \mathrm{OH}^{-}
$$

Leaching followed by solvent extraction with $\beta$-diketonebased compound was performed and the same organic was recycled for all trials. Extraction efficiencies with organic concentration of $25 \%$ performed well when compared to that of $20 \%$. Stripping efficiencies were also quite good. Stripper with initial acidity of $150 \mathrm{~g} / \mathrm{l}$ was used for stripping.

No impact of zinc was observed on solvent extraction and generated copper sulphate containing zinc in a range of 0.1 $0.5 \mathrm{~g} / \mathrm{l}$ is acceptable as an activator for sphalerite flotation in our captive mines. Results tabulated below.

Table 5. Solvent extraction trials for cyclic leachate.

\begin{tabular}{|c|c|c|c|c|c|c|c|c|}
\hline \multicolumn{2}{|c|}{ Aqueous feed } & \multirow[t]{2}{*}{ Org Con. } & \multicolumn{2}{|c|}{ Final raffinate } & \multirow{2}{*}{$\begin{array}{l}\text { Extraction eff \% } \\
\mathrm{Cu}\end{array}$} & \multicolumn{2}{|c|}{ Stripper g/l } & \multirow{2}{*}{$\begin{array}{l}\text { Stripping eff\% } \\
\mathrm{Cu}\end{array}$} \\
\hline $\mathrm{Cu}$ g/l & Zn g/l & & $\mathrm{Cu}$ g/l & Zn g/l & & $\mathrm{Cu}$ & $\mathbf{Z n}$ & \\
\hline 23.3 & 1.23 & $25 \%$ & 2.78 & 1.21 & 88.04 & 60.68 & 0.05 & 98.8 \\
\hline 30.2 & 1.41 & $25 \%$ & 1.2 & 1.16 & 93.65 & 53.75 & 0.24 & 94.3 \\
\hline 29.9 & 1.39 & $25 \%$ & 1.09 & 1.2 & 94.12 & 68 & 0.35 & 99.7 \\
\hline 25.7 & 1.51 & $25 \%$ & 2.47 & 1.43 & 86.51 & 46.65 & 0.15 & 95.2 \\
\hline 27.2 & 1.61 & $25 \%$ & 2.14 & 1.21 & 92.15 & 51.9 & 0.50 & 94.0 \\
\hline
\end{tabular}

O/A 1:1, stripper acidity - 120 g/1, S/LO 2:1.

\section{Conclusions}

A process was designed, developed and implemented for the recovery of copper from cold purification cake which was previously sold at lower realization. The leaching kinetics of the cold purification cake in ammonical carbonate solution was validated through shrinking core model. From the kinetics model chemical reaction at unreacted core is the rate controlling step which was further confirmed by the activation energy that was within the range for reaction rate controlling step.
To decrease the impact of w/s Zinc in leaching and solvent extraction, initial washing was provided for purification cake. Reagent concentrations, temperature, agitation RPM, pulp density parameters were optimized and finally leaching followed by solvent extraction trials were conducted in series. Further with optimized parameters, a stream has been designed and developed at CRP Pyro, in which process has been successfully implemented and continuously running without any hiccups. Until now 300 MT of Purification cake has been treated, and generated 3900 MT of copper sulphate $(55 \mathrm{~g} / \mathrm{l} \mathrm{Cu})$, with final $\mathrm{Cu}$ recoveries between $87-90 \%$. 


\section{Nomenclatures}

$\mathrm{A}$
$\mathrm{b}$
$\mathrm{c}_{\mathrm{A}}$
$\mathrm{D}_{\mathrm{e}}$
$\mathrm{E}_{\mathrm{a}}$
$k_{\mathrm{c}}$
$k_{\mathrm{d}}$
$k_{\mathrm{r}}$
$k_{\mathrm{S}}$
$R$
$t$
$T$
$x$
$\rho_{\mathrm{s}}$
$r_{0}$
$\mathrm{CO}_{2}$
$\mathrm{NH}_{3}$

Pre-exponential factor in Arrhenius equation

Stoichiometric coefficient in eq [8]

Concentration of fluid reactant $(\mathrm{mol} / \mathrm{m})$

Effective diffusivity $\left(\mathrm{m}^{2} / \mathrm{s}\right)$

Activation energy $(\mathrm{J} / \mathrm{mol})$

Liquid-solid mass transfer coefficient $(\mathrm{m} / \mathrm{s})$

Apparent rate constant for product layer diffusion $\left(\mathrm{s}^{-1}\right)$

Apparent rate constant for surface chemical reaction $\left(\mathrm{s}^{-1}\right)$

Intrinsic reaction rate constant

Mole gas constant $(8.3145 \mathrm{~J} /(\mathrm{mol} \cdot \mathrm{K}))$

Time (h or s)

Temperature $(\mathrm{K}) /{ }^{\circ}$ centigrade

Fraction of extraction

Density of solid

Initial particle radius (m)

carbon dioxide

Ammonia

\section{Acknowledgements}

The authors would like to acknowledge Hindustan Zinc Limited for providing a fostering environment for this research and permission to publish the data.

\section{References}

[1] Robert J S, The Extractive Metallurgy of Zinc, The Australasian institute of Mining and Metallurgy, Spectrum Series, volume number 13, 2005. Pp. 93-112.

[2] Habashi F, Handbook of Extractive Metallurgy, Wiley, New York. 1997.

[3] Hackl R P, Dreisinger D B, Peters E, King J A, Passivation of chalcopyrite during oxidative leaching in sulfate media. $[\mathrm{J}]$ Hydrometallurgy, 1995. 39: 25-48.

[4] Ghosh M K, Das R P, Biswas, A K, Oxidative ammonia leaching of spharelite Part I: Noncatalytic kinetics International Journal of Mineral Process, 2002. 66: 241-254.

[5] Wang X, Chen Q, Hu H, Yin Z, Xiao Z, Solubility prediction of malachite in aqueous ammoniacal ammonium chloride solutions at $25^{\circ} \mathrm{C}$. Hydrometallurgy, 2009. 99: 231-237.

[6] Biswas A K, Davenport W G, Extractive Metallurgy of
Copper, International series on Material Science and Technology; volume 20. 1980.

[7] Konishi H, Selective Separation and Recovery of Copper from Iron and Copper mixed waste by Ammonia solution. Graduate school of engineering, Osaka university.

[8] John R S, Matthew D S, Practical aspects of copper solvent extraction from acidic leach liquors, zeneca specialties, acorga metal extraction products blackley, manchester U.K.

[9] Levenspiel O, Chemical Reaction Engineering [m]. 3rd edition. New York: Wiley. 1998.

[10] Baba A A, Ghosh M K, Pradhan S R, Rao D S, Baral A, Adekola F A," Characterization and kinetic study on ammonia leaching of complex copper ore" Trans. Nonferrous met. Soc. of China, 2014. 24, 1587-1595.

[11] Terézia V, Tamás I, Materials science and engineering, 2013. Volume 38/1. Pp. 61-71.

[12] Sankum N, Noppadol Y, Chu Yong C and Torranin C, "Characterisation of Zinc Plant, Cold-Purification Filter Cake and Leaching of Indium by Aqueous Sulphuric Acid Solution" Chiang Mai J. Sci. 2015; 42 (3): 718-729.

[13] Manivannan S, David H, Piet N L L, Heinrich A. H, Luiz H A F, Eric D H; Leaching and selective copper recovery from acidic leachates of Três Marias zinc plant (MG, Brazil) metallurgical purification residues; Journal of Environmental Management; Volume 177, 15 July 2016, Pages 26-35. 